\title{
Why do young Hispanic women take sexual risks? Psychological and cultural factors for HIV prevention
}

Cristina Giménez-García, PhD

Estefanía Ruiz-Palomino, $\mathrm{PhD}$

María Dolores Gil-Llario, PhD

Rafael Ballester-Arnal, PhD

Claudia Castañeiras, $\mathrm{PhD}$

Cristina Giménez-García*, PhD, is an Assistant Professor, Universitat Jaume I. Departamento de Psicología Básica, Clínica y Psicobiología, Castellón, Spain (gimenezc@psb.uji.es). Estefanía Ruiz-Palomino, PhD, is an Assistant Professor, Universitat Jaume I, Departamento de Psicología Básica, Clínica y Psicobiología, Castellón, Spain. María Dolores Gil-Llario, $\mathrm{PhD}$, is a Professor, Universitat de València, Estudi General, Departamento de Psicologia Evolutiva y de la Educación, Valencia, Spain. Rafael Ballester-Arnal, PhD, is a Professor, Universitat Jaume I, Departamento de Psicología Básica, Clínica y Psicobiología, Castellón, Spain. Claudia Castañeiras, $\mathrm{PhD}$, is a Lecturer, Universidad Nacional de Mar del Plata, Facultad de Psicología, Buenos Aires, Argentina.

*Corresponding author: Cristina Giménez-García, e-mail: gimenezc@psb.uji.es

Disclosure. The authors report no real or perceived vested interests that relate to this article that could be construed as a conflict of interest.

Keywords. Hispanic women; HIV; self-efficacy; sexual risk; sexual sensation seeking; young women 


\begin{abstract}
Young Hispanic women have been particularly affected by HIV. For this reason, we analyzed the influence of cognitive factors, dispositional variables, and gender culture on the HIV risks of 2 groups of Hispanic women. Young Argentinian and Spanish women $(N=342)$ completed the AIDS Prevention Questionnaire, the Spanish version of the Sexual Compulsivity Scale, and the Spanish version of the Sexual Sensation Seeking Scale in order to evaluate knowledge of HIV transmission, HIV, and condom use; self-efficacy; safe-sex intention and safe sex; as well as Sexual Sensation Seeking and Sexual Compulsivity traits. Our findings support a different pattern of HIV risk based on gender inequality, although self-efficacy and sexual sensation seeking seem to have been the main important predictors of unsafe sex and HIV risk. Social and psychological factors should be considered to design HIV prevention strategies aimed at young Hispanic women.
\end{abstract}

Keywords. Hispanic women; HIV; self-efficacy; sexual risk; sexual sensation seeking; young women 
Why do young Hispanic women take sexual risks? Psychological and cultural factors for HIV prevention

Currently, half of the people living with HIV (PLWH) are women and most of them have trouble accessing health care (Joint United Nations Programme on HIV/AIDS [UNAIDS], 2016). However, risk factors for HIV infection have not been studied in depth to deal with this situation, not even in sexual transmission, which is the most prevalent cause for HIV infection in women (Ballester-Arnal, Gil-Llario, Castro-Calvo \& Giménez-García, 2016; Cianelli \& Villegas, 2016).

In particular, women who are socialized in gendered societies, in which cultures give more social power and autonomy to men, while delegating a more dependent and passive position to women, experience higher risk for HIV sexual transmission (Giménez-García, Ballester-Arnal, Gil-Llario, Cárdenas-López, \& Duran-Baca, 2013). For example, in the United States, the rate of HIV in Hispanic women (i.e., with ancestry from a Spanishspeaking country or culture) have more than three times the rate of HIV found in nonHispanic White women (Centers for Disease Control and Prevention, 2015). These rates are higher for young Hispanic women in Latin America, North America, and Europe (UNAIDS, 2016).

Different factors may influence this situation, from social determinants of health to biological predisposition. Regarding personal factors, some studies have emphasized the role of psychological variables such as sexual sensation seeking (having a desire for sexual stimulation and arousal) that may facilitate higher fear of condom negotiation or diminish self-efficacy to refuse unsafe sex (Gil-Llario, Ruiz-Palomino, Ballester-Arnal \& MorellMengual, 2016; Voisin, Tan \& DiClemente, 2013). HIV risk behaviors have also been linked to sexual compulsivity and hypersexuality (Miner \& Coleman, 2013). Regarding cognitive variables, factors such as knowledge, attitudes toward condoms, self-efficacy, risk 
perception, and fear of HIV infection may also promote riskier behaviors in women from Spanish-speaking countries or cultures (Marín, 2003; Villegas, Cianelli, Santisteban, Lara \& Vargas, 2016).

Culture also plays an important role in sexual health and HIV prevention for women. For example, Hispanic culture maintains some traditions and values, such as Catholicism (Cianelli \& Villegas, 2016) or machismo (Bowleg, Belgrave, \& Reisen, 2000), that facilitate a dependent social position for women who experience lower sexual self-efficacy and perceive higher barriers to negotiate condom use. Hispanic culture seems to increase the risk of HIV infection among women. In particular, this situation prevails in women in steady relationships who mainly report lower perceived HIV risk due to the myth of romantic love (Lara, Cianelli, \& Ferrer, 2008). Another risky situation is alcohol consumption that is normalized in Hispanic cultures. Authors such as Vagenas et al. (2013) have emphasized the connection between alcohol consumption and sexual risk-taking in adolescent and young women from Latin American countries.

Despite common traits shared by young women from Spanish-speaking countries or cultures, studies have also shown different risk profiles based on gender inequality, measured by the Gender Inequality Index (United Nations Development Programme [UNDP], 2016). UNDP created this index to assess gender inequality across the world in 152 countries. It has revealed three dimensions of disadvantage in women (reproductive health, empowerment, and the labor market), which ranges from 0 (equality) to 1 (women fare as poorly as possible) and varies across countries from 0.02 to 0.73 . Gender inequality measured at a higher value describes a country with more disparities between males and females, more disadvantages for women, and higher inequality. Spain's gender inequality scores reveal more equal positions between the genders (score of 0.08) than Argentina (score of 0.36). In order to identify the level of gender inequality for Spanish and Argentinian women, we used the Gender 
Inequality Index (UNDP, 2016). For example, Giménez-García et al. (2013) found that Hispanic women who were socialized in a context with more gender inequality, such as Mexican women, revealed a riskier profile than Spanish women, who were socialized in a more gender equal context. Therefore, women from Spanish-speaking countries may be more diverse than past studies have revealed regarding risk-taking sexuality and HIV infection.

Most of the studies focused on this group of women, however, have not distinguished their possible heterogeneity. For this reason, the main purpose of our study was to evaluate the role of different HIV risk factors (cognitive factors, personality traits as dispositional variables, and gender inequality) in young Argentinian and Spanish women.

\section{Method}

We disseminated information about the study during outreach activities addressing promotion of sexual health that were delivered in education centers in Argentina and Spain. When young women showed an interest in taking part in the study, we made an appointment with her to visit our lab in order to provide more information about the conditions of participation. We explained that the study was voluntary, and that the data collected would be confidential and anonymous. We also discussed the time contribution needed from her. If the young woman agreed to participate, she gave informed consent. After that, she took selfadministered questionnaires, in 30-40 minutes. A trained member of our team supported participants in case they did not understand any of the questions. Our study was in compliance with the ethical standards of the institutional research committee of University Jaume I and the 1964 Helsinki declaration.

Eligibility criteria for our study were: (a) being a woman, (b) being a native of Argentina or Spain, (c) ranging in age between 18 and 26 years, and (d) filling out the instrument completely. One hundred and fifty participants took part in Argentina and 200 in Spain. However, only $97.7 \%$ (342 participants, 55.8\% of Spanish and 44.2\% of Argentinian) 
met the selection criteria and were included in the data analyses.

\section{Instruments}

The AIDS Prevention Questionnaire (Ballester, Gil, \& Giménez, 2007) examines risk behavior indicators for HIV transmission such as knowledge, beliefs and attitudes, selfefficacy, safe sex behavioral intention and behavior, as well as social stigma. In addition, this instrument explores sexual experience, sexual orientation, and marital status. The questionnaire has 65 items with different formats: Likert scale, yes/no-type questions, open questions, and multiple-choice questions.

In particular, we used seven items to explore knowledge (Can HIV be transmitted by vaginal sex/oral sex/anal sex?), perceived information (How do you think your level of HIV information is?), perceived risk of HIV infection (What is the probability of getting infected with HIV?), perceived fear of being infected (What level of fear do you feel of being infected with HIV?), condom barriers (Mark the main barriers for condom use: price, breakage, lower sensitivity, discomfort, inexperience, relationship problems, etc.), self-efficacy (Would you feel comfortable buying condoms/negotiating condom use/managing partner reaction/using condoms after alcohol consumption/feeling calm/stopping when you are excited to use a condom?), and condom use (Have you used condoms with a steady partner, with a casual partner, and after alcohol consumption?). We also used one item for sexual experience (What types of sexual practices have you used? Masturbation, mutual masturbation, vaginal sex, oral sex, anal sex, other type of sexual practices).

The Spanish version of the Sexual Sensation Seeking Scale (Kalichman \& Rompa, 1995) by Ballester-Arnal, Ruiz-Palomino, Espada-Sánchez, Morell-Mengual and Gil-Llario (2018) evaluates the disposition to seek new or risky sexual stimulation through an 11-item scale ranging from 1 (uncharacteristic of me) to 4 (very characteristic of me). The internal consistency of the Spanish adaptation was .70 (Ballester-Arnal et al., 2018). 
The Spanish version of the Sexual Compulsivity Scale (Kalichman \& Rompa, 1995) by Ballester, Gómez, Gil, and Salmerón (2013) examines the tendency to experiment sexually and hypersexuality in a nine-item scale, ranging from 1 (uncharacteristic of me) to 4 (very characteristic of me). The Spanish version had an Alpha coefficient of .837 and a correlation value of 0.725 for test-retest reliability (Ballester et al., 2013).

\section{Data Analyses}

To examine differences between Argentinian and Spanish women for cognitive and dispositional variables, we used differential analyses ( $X^{2}$ test, $t$ test). To determine possible predictors of safe sex in women, we performed logistic regression analyses. Regarding independent variables about cognitive dimension, we examined HIV knowledge about sexual routes of HIV transmission, as well as perceived information, that is, the perception of being well informed. We analyzed attitudes about fear of HIV infection (distress about being infected with HIV), evaluation of risk for HIV infection (perceived probability of becoming infected), and condom barriers (perceived disadvantages of using a condom). Moreover, we studied sexual self-efficacy that involved the personal evaluation about a participant's own ability to have safe sex. Concerning disposition variables, we evaluated sexual sensation seeking that involved the disposition to seek new or risky sexual stimulation. We explored sexual compulsivity (the tendency to experiment sexually and hypersexuality). Moreover, in line with past studies (Giménez-García et al., 2013), we considered gender inequality based on the Gender Inequality Index (UNDP, 2016).

We also evaluated condom use by asking about a systematic use of condoms with a steady partner, a casual partner, and after alcohol consumption. We used the AIDS Prevention Questionnaire (Ballester et al., 2007) to evaluate independent variables related to HIV infection (information, attitudes, and self-efficacy), as well as the dependent variable (condom use in different sexual contexts), and sexual experience. We examined dispositional 
variables with the Spanish version of the Sexual Sensation Seeking Scale (Ballester-Arnal et al., 2018; Kalichman \& Rompa, 1995) and the Spanish version of the Sexual Compulsivity Scale (Ballester et al., 2013; Kalichman \& Rompa, 1995).

\section{Results}

Three hundred and forty-two young women from Argentina (44\% of participants) and Spain (56\% of participants) took part in our study (see Table 1$)$. There were no statistically significant differences in age; the mean age of the Argentinian women was 22.39 years $(S D=$ $2.15)$ and of Spanish women was 22.03 years $(S D=2.73)$. Moreover, there were no significant differences for sexual orientation; Argentinian and Spanish women self-identified as heterosexual most often, followed by bisexual in Spanish women and homosexual in Argentinian women. Similarly, most of the women were in steady relationships, $69.2 \%$ of Spanish women and $68 \%$ of Argentinian women. Participants belonged to the middle social class and all of them had secondary educations.

\section{Behavior and Disposition Variables}

Concerning sexual experience, the Argentinian and Spanish women had similar experiences except for anal sex, which was more common for Argentinian women (see Table 2). The most frequent practices were vaginal and oral sex; anal sex and masturbation were reported less often. Moreover, both Argentinian and Spanish women revealed similar percentages for consumption of pornography, and most had weekly sexual contacts in Argentina (74.4\%) and Spain $\left(81.7 \% ; X^{2}=3.92 ; p=.141\right)$.

In relation to dispositional variables, Spanish women revealed higher scores in sexual sensation seeking $(M=25.05, S D=4.76)$ than Argentinian women. This difference was statistically significant $(t=8.66 ; p=.001)$. Spanish women also had higher scores in sexual compulsivity $(M=12.69, S D=3.01)$ than Argentinian women $(M=11.00, S D=2.04)$, revealing statistically significant differences $(t=4.20 ; p=.001)$. 


\section{Cognitive Variables: Information, Beliefs, and Self-Efficacy}

Spanish and Argentinian women revealed statistically significant differences on certain cognitive variables (see Table 3). First, Argentinian women exceeded Spanish women in self-identifying as well informed (90\% of Argentinian and $67.5 \%$ of Spanish women) and this difference obtained statistical significance $\left(X^{2}=18.03 ; p=.001\right)$. Regarding real knowledge, Argentinians revealed higher levels of information, reporting oral sex as a route for HIV transmission (75.3\% vs. 56.2\% of Spanish women) with significant statistical differences $\left(X^{2}=8.83 ; p=.003\right)$. Contrarily, Argentinian and Spanish women showed similar misinformation related to vaginal (1.3\% of Argentinian and $1.2 \%$ of Spanish women; $X^{2}=$ $0.01 ; p=.958)$ and anal sex transmission routes for HIV (18\% of Argentinian and $20 \%$ of Spanish women; $\left.X^{2}=0.13 ; p=.711\right)$. Regarding HIV perceptions, Argentinian and Spanish women also had similar scores. In general, few of the women in our study reported perceptions of high risk for HIV infection (4.1\% of Argentinian and 3.8\% of Spanish women; $\left.X^{2}=0.01 ; p=.903\right)$, but the percentage increased for high fear of being HIV infected $(64.2 \%$ of Argentinian and $63.8 \%$ of Spanish women; $\left.X^{2}=0.01 ; p=.947\right)$.

In addition, perceived barriers to condom use revealed statistically significant differences. More Spanish women reported perceived barriers than Argentinian women, revealing statistically significant differences (71.2\% of Spanish vs. 58\% of Argentinian women; $\left.X^{2}=3.91 ; p=.048\right)$. Regarding the type of barrier, the most common barrier for both groups were losing sensitivity (55\% of Spanish, 39.3\% of Argentinian), possible breakage of condom (38.8\% of Spanish, 17.3\% of Argentinian), and relationship problems (30\% of Spanish, $20 \%$ of Argentinian). In self-efficacy, there were statistically significant differences for condom use negotiation, in which more Argentinian women (57.3\%) reported feeling competent than Spanish women $\left(42.5 \% ; X^{2}=4.60 ; p=.032\right)$. Nevertheless, both had lower scores for buying condoms (29.3\% of Argentinian and 35\% of Spanish women; $X^{2}=0.78 ; p=$ 
.377 ) and stopping when I'm excited to use a condom (34.7\% of Argentinian and 28.8\% of Spanish women; $X^{2}=0.83 ; p=.362$ ). Concerning intention to have safe sex, Spanish and Argentinian women had similar scores. Both reported a 100\% safe intention only for casual sex, revealing a higher risk profile for steady relationships (52\% of Argentinian and $45 \%$ of Spanish women; $\left.X^{2}=0.23 ; p=.634\right)$ and having sex under alcohol effects $(93.3 \%$ of Argentinian and $75 \%$ of Spanish women; $\left.X^{2}=2.02 ; p=.154\right)$.

\section{Safe Sex: Cognitive Variables, Dispositional Variables, Level of Inequality, and Systematic Use of Condoms}

In general, Spanish women exceeded Argentinian women in safe sex practices, revealing statistically significant differences. In particular, differences were relevant for steady partners, in which $73.4 \%$ of Spanish women reported safe sex versus $34.7 \%$ of Argentinian women $\left(X^{2}=51.48 ; p=.001\right)$, followed by having safe sex after alcohol consumption, in which $83.3 \%$ of Spanish women reported safe sex versus $68 \%$ of Argentinian women $\left(X^{2}=11.04 ; p=.001\right)$, and safe sex in a casual relationship, in which $91.7 \%$ of Spanish women reported safe sex versus $80.7 \%$ of Argentinian women $\left(X^{2}=8.91\right.$; $p=.003)$.

Concerning possible predictors for safe sex, as Table 4 shows, $53 \%$ of variance of having sex in a steady relationship $\left(X^{2}=38.31 ; p=.001\right)$ was explained by lower barriers to condom use $(B=-.185 ; O R=.320 ; I C=.444,1.557)$, higher self-efficacy $(B=.113 ; O R=$ $.186 ; I C=.778,1.611)$, lower sexual sensation seeking $(B=-.390 ; O R=.130 ; I C=0.524$, $0.874)$, and lower sexual frequency $(B=-.627 ; O R=.209 ; I C=.355, .805)$. Regarding having sex in casual relationships, $18 \%$ of variance $\left(X^{2}=9.83 ; p=.043\right)$ was explained by lower barriers to condom use $(B=-.019 ; O R=.280 ; I C=.567,1.690)$, higher self-efficacy $(B$ $=.407 ; O R=.180 ; I C=1.050,2.130)$, lower sexual sensation seeking $(B=-.126 ; O R=.063$; $I C=0.770,0.998)$, and lower sexual frequency $(B=-.004 ; O R=.197 ; I C=.670,1.460)$. 
Concerning having sex after alcohol use, $17 \%$ of variance $\left(X^{2}=21.15 ; p=.001\right)$ was explained by lower barriers to condom use $(B=-.175 ; O R=1.350 ; I C=.644,1.093)$, higher self-efficacy $(B=.239 ; O R=.091 ; I C=1.062,1.520)$, lower sexual sensation seeking $(B=$ $.422 ; O R=.277 ; I C=0.887,2.620)$, lower sexual frequency $(B=-.100 ; O R=.037 ; I C=$ $.842, .973)$ and being Spanish $(B=.937 ; O R=.447 ; I C=1.062,6.133)$. Therefore, variables related to information, beliefs, and attitudes about HIV did not influence these participants.

\section{Discussion}

Our study analyzed risk-taking behaviors between two groups of young Hispanic women who differed in HIV risk on the important variables of gender inequality, underlying cognitive factors, and dispositional variables, in particular, on risky contexts such as having sex after alcohol consumption, steady partners, and casual relationships.

In spite of some differences, our findings supported studies that emphasized a risky profile among women from Spanish-speaking countries and cultures (Bowleg et al., 2000; Cianelli \& Villegas, 2016). In our study, young Argentinian and Spanish women both reported misinformation about HIV transmission routes, low risk perception, fear of becoming HIV infected, important perceived barriers for condom use, low self-efficacy, and intention of having safe sex in a steady relationship. According to socio-cognitive models (Ajzen \& Fishbein, 1980; Bandura, 1994; DiClemente, Santelli \& Crosby, 2009), all of these variables may increase HIV infection risks in sexual behaviors. Accordingly, this relationship might contribute to higher HIV rates among Hispanic women compared to other cultures (Centers for Disease Control and Prevention, 2015; UNAIDS, 2016).

Nevertheless, we found differences regarding safe sex behaviors between the Argentinian and Spanish women in our study. In general, in line with the findings of Giménez-García et al. (2013), there were differences based on gender inequality. In particular, Spanish women revealed more safe sex practices for steady and casual partners, as 
well as having sex after alcohol consumption, than Argentinian women. Regardless of these differences, both Spanish and Argentinian women reported higher risk in a steady partner context, as Lara et al. (2008) also found. This might be related to the traditional role of Hispanic women, as well as romantic love stereotypes, which may promote more dependence on a partner and lower possibilities to negotiate condom use (Saura et al., in press). At the same time, alcohol consumption, which has a high prevalence in Hispanic youth (Pons \& Buelga, 2011), has been related to unsafe sex for HIV (Vagenas et al., 2013). Therefore, special attention should be paid to both alcohol use and unsafe sex for HIV prevention interventions.

Our findings revealed the relevance of cognitive and personality traits, as well as gender inequality as predictors for safe sex. In line with past studies (Bowleg et al., 2000; Gil-Llario et al., 2016), the Argentinian and Spanish women in our study were more likely to have safe sex when they reported higher convictions about their own abilities to have safe sex and lower dispositions to seek new or risky sexual stimulation. Moreover, being socialized in a more gender-equal society promoted higher rates of safe sex after alcohol consumption.

\section{Limitations}

Some limitations should be considered in these results. First, the questionnaires we used were self-report measures that might facilitate social desirability responses. In addition, future studies should increase the number of participants and diversify for geographic location and sociodemographic profile.

\section{Conclusions}

Regardless of these limitations, our study provided relevant findings for HIV prevention in two groups of young Hispanic women. Our results demonstrated how risky profiles for HIV infection were still present in young Hispanic women. Moreover, the risky profile involved a great complexity of underlying risk factors that included cognitive 
variables, personality traits, and gender socialization. In addition, the factors should be weighted differently depending on the sexual context. Our findings should be considered when developing effective strategies to prevent HIV infection in young Hispanic women. 


\section{References}

Ajzen, I., \& Fishbein, M. (1980). Understanding attitudes and predicting social behavior. Englewood Cliffs, NJ: Prentice Hall.

Ballester-Arnal, R., Gil-Llario, M.D., Castro-Calvo, J., \& Giménez-García, C. (2016). HIVRisk Index: Development and validation of a brief risk index for Hispanic young people. AIDS \& Behavior, 20, 1796-1807. doi:10.1007/s10461-016-1411-0

Ballester, R., Gil, M. D., \& Giménez, C. (2007). El Cuestionario de Prevención del Sida (CPS): Análisis de la Fiabilidad y Validez (The AIDS Prevention Questionnaire: Analyses of reliability and validity). Communication presented at $X$ Congreso Nacional sobre el Sida, San Sebastián, Spain.

Ballester-Arnal, R., Ruiz-Palomino, E., Espada-Sánchez, J.P., Morell-Mengual, V. \& GilLlario, M.D. (2018). Psychometric properties and validation of the sexual sensation seeking scale in Spanish adolescents: Brief screening method for use in research and clinical practice. Personality and Individual Differences, 122, 47-54. doi:10.1016/j.paid.2017.10.006

Ballester, R., Gómez, S., Gil, M.D. \& Salmerón, P. (2013). Sexual compulsivity scale: Adaptation and validation in Spanish population. Journal of Sex \& Marital Therapy, 6, 526-540. doi:10.1080/0092623X.2012.665816

Bandura, A. (1994). Social cognitive theory and exercise of control over HIV infection. In R. J. DiClemente \& J. L. Peterson (Eds.), Preventing AIDS: Theories and methods of behavioral intervention (pp. 25-60). New York, NY: Plenum Press.

Bowleg, L., Belgrave, F. Z., \& Reisen, C.A. (2000). Gender roles, power strategies, and precautionary sexual self-efficacy: Implications for Black and Latina women's HIV/AIDS protective behaviors. Sex Roles, 42, 613-635. doi:10.1023/A:100709942 Centers for Disease Control and Prevention. (2015). HIV Surveillance Report, 2013. 
Retrieved from http://www.cdc.gov/hiv/library/reports/surveillance

Cianelli, R., \& Villegas, N. (2016). Social determinants of health for HIV among Hispanic women. Hispanic Health Care International, 14, 4-9.

doi:10.1177/1540415316629672

Gil-Llario, M.D., Ruiz-Palomino, E., Ballester-Arnal, R., \& Morell-Mengual, V. (2016). Influence of sexual sensation seeking, sexual compulsivity and sexual pleasure in condom use among Spanish youth: Implications for HIV interventions. Journal of Preventive Medicine Care, 3, 1-8. doi:10.14302/issn.2474-3585.jpmc-16-1198

Giménez-García, C., Ballester-Arnal, R., Gil-Llario, M.D., Cárdenas-López, G. \& DuranBaca, X. (2013). Culture as an influence on the perceived risk of HIV infection: A differential analysis comparing young people from Mexico and Spain. Journal of Community Health, 38, 434-442. doi:10.1007/s10900-012-9636-y

DiClemente, R., Santelli, J., \& Crosby, R. (2009). Adolescent health. Understanding and preventive risk behaviors. San Francisco, CA: Jossey-Bass

Joint United Nations Programme on HIV/AIDS. (2016). Global AIDS update. Retrieved from http://www.unaids.org/sites/default/files/media asset/global-AIDS-update2016 en.pdf

Kalichman, S. C., \& Rompa, D. (1995). Sexual sensation seeking and sexual compulsivity scales: Reliability, validity, and predicting HIV risk behavior. Journal of Personality Assessment, 65, 586-601. doi:10.1207/s15327752jpa6503_16

Lara, L., Cianelli, R., \& Ferrer, L (2008). Comunicación de pareja y VIH en mujeres en desventaja (Partner communication and HIV in low income women). Revista Horizonte de Enfermería, 19, 35-43.

Marín, B.V. (2003). HIV prevention in the Hispanic community: Sex, culture, and empowerment. Journal of Transcultural Nursing, 14, 186-192. 
doi:10.1177/1043659603014003005

Miner, M. H., \& Coleman, E. (2013). Compulsive sexual behavior and its relationship to risky sexual behavior. Sexual Addiction \& Compulsivity, 20, 127-138. doi:10.1080/10720162.2013.768133

Pons, J., \& Buelga, S. (2011). Factors associated with youth alcohol consumption: A review from a psychosocial and ecological perspective. Psychosocial Intervention, 20, 75-94. doi:10.5093/in2011v20n1a7

United Nations Development Programme. (2016). Human development data (1990-2015). Gender Inequality Index. Retrieved from http://hdr.undp.org/en/data

Saura, S., Jorquera, V., Rodríguez, D., Mascort, C., Castellà, I., \& García, J. (in press). Gender meanings of the risk of sexually transmitted infections/HIV transmission among young people. Atención Primaria. doi:10.1016/j.aprim.2017.08.005

Vagenas, P., Lama, J., Lukford, K., Gonzales, P., Sánchez, J., \& Altice, F.L. (2013). A systematic review of alcohol use and sexual risk-taking in Latin America. Revista Panamericana de Salud Pública, 34, 267-274.

Voisin, D., Tan, K. \& DiClemente, R.J. (2013). A longitudinal examination of the relationship between sexual sensation seeking and STI-related risk factors among African American females. AIDS Education and Prevention, 25, 124-134. doi:10.1521/aeap.2013.25.2.124

Villegas, N., Cianelli, R., Santisteban, D., Lara, L., \& Vargas, J. (2016). Factores que influencian la adquisición de infecciones de transmisión sexual y VIH en mujeres jóvenes Chilenas que participaron en la intervención online I-STIPI (Factors that influence the acquisition of sexually transmitted infections and HIV in Chilean young women who participated in the online intervention I-STIPI). Hispanic Health Care International, 14, 47-56. doi:10.1177/1540415316629682 


\section{Key Considerations}

- It is important to examine riskier profiles among young Hispanic women based on social and psychological traits such as self-efficacy, sexual sensation seeking, and gendered cultures.

- Young Hispanic women need prevention interventions that promote safe sex and, consequently, increase the effectiveness of these interventions.

- Young Hispanic women are often excluded in programs that provide sexual health assistance. More health facilities that provide HIV prevention aimed at young Hispanic women are needed. 
Table 1

Participant Demographics at Baseline $(\mathrm{N}=350)$

\begin{tabular}{|c|c|c|c|c|}
\hline \multicolumn{2}{|c|}{ Characteristics } & Argentina & Spain & Differential \\
\hline \multirow{2}{*}{\multicolumn{2}{|c|}{ Age }} & $M=22.39$ & $M=22.03$ & $t=1.37$ \\
\hline & & $S D=2.15$ & $S D=2.73$ & $p=.171$ \\
\hline Education level (\%) & Secondary & 100 & 100 & -- \\
\hline Social class $(\%)$ & Middle & 100 & 100 & -- \\
\hline Relationshin (\%) & Steady & 68 & 69.2 & $X^{2}=0.03$ \\
\hline \multirow{3}{*}{$\begin{array}{l}\text { Sexual orientation } \\
\qquad(\%)\end{array}$} & Single & 32 & 30.8 & $p=.850$ \\
\hline & Bisexual & 0 & 2.5 & \multirow{2}{*}{$\begin{array}{c}X^{2}=3.27 \\
p=.195\end{array}$} \\
\hline & Heterosexual & 99.3 & 96.3 & \\
\hline
\end{tabular}


Table 2

Differential Analysis Between Argentinian and Spanish Women in Sexual Experience

\begin{tabular}{cccc}
\hline & Spanish & Argentinian & \\
Sexual behavior & women & women & $X^{2}(p)$ \\
& $(\%)$ & $(\%)$ & \\
\hline Masturbation & 55 & 54.6 & $.001(.982)$ \\
Mutual masturbation & 66.1 & 72 & $.755(.385)$ \\
Vaginal sex & 90.8 & 92.7 & $.210(.647)$ \\
Oral sex & 75.2 & 81.7 & $1.14(.285)$ \\
Anal sex & 17.4 & 31.7 & $5.29(.021)$ \\
Use of pornography & 17.1 & 9.8 & $2.12(.145)$ \\
\hline
\end{tabular}


Table 3

Differential Analysis Between Argentinian and Spanish Women in Variables Related to HIV Infection

\begin{tabular}{|c|c|c|c|}
\hline Variables & $\begin{array}{c}\text { Spanish } \\
\text { women (\%) }\end{array}$ & $\begin{array}{l}\text { Argentinian } \\
\text { women }(\%)\end{array}$ & $X^{2}(p)$ \\
\hline Perception of being well-informed & 67.5 & 90 & $18.03(.001)$ \\
\hline Identify as HIV transmission route: Oral sex & 56.2 & 75.3 & $8.83(.003)$ \\
\hline Identify as HIV transmission route: Vaginal sex & 98.8 & 98.7 & $0.01(.958)$ \\
\hline Identify as HIV transmission route: Anal sex & 80 & 82 & $0.13(.711)$ \\
\hline Perception of high risk of getting HIV & 3.8 & 4.1 & $0.01(.903)$ \\
\hline High fear of being HIV infected & 63.8 & 64.2 & $0.01(.947)$ \\
\hline Perception of condom barriers & 71.2 & 58 & $3.91(.048)$ \\
\hline Safe-sex intention in steady relationship & 45 & 52 & $0.23(.634)$ \\
\hline Safe-sex intention in casual relationship & 100 & 100 & - \\
\hline Safe-sex intention after alcohol use & 75 & 93.3 & $2.02(.154)$ \\
\hline Self-efficacy for buying condoms & 35 & 29.3 & $0.78(.377)$ \\
\hline Self-efficacy for negotiating condom use & 42.5 & 57.3 & $4.60(.032)$ \\
\hline Self-efficacy for managing partner reactions & 58.8 & 67.3 & $1.67(.196)$ \\
\hline $\begin{array}{l}\text { Self-efficacy for using condoms after alcohol } \\
\text { consumption }\end{array}$ & 40 & 38.7 & $0.04(.844)$ \\
\hline Self-efficacy for feeling calm & 47.5 & 39.3 & $1.42(.232)$ \\
\hline Self-efficacy for stopping when I'm excited to & 28.8 & 34.7 & $0.83(.362)$ \\
\hline
\end{tabular}


Table 4

Regression Analysis for Safe Sex (Condom Use) Including Gendered Inequality, Cognitive Factors, and Dispositional Variables

\begin{tabular}{|c|c|c|c|c|c|c|c|}
\hline \multirow[t]{2}{*}{ Safe sex } & \multirow[b]{2}{*}{ Barriers to condom use } & \multirow{2}{*}{$\begin{array}{c}B \\
-.185\end{array}$} & \multirow{2}{*}{$\begin{array}{l}\text { OR } \\
.320\end{array}$} & \multicolumn{2}{|c|}{$I C$} & \multirow[t]{2}{*}{$R^{2}$} & \multirow[t]{2}{*}{$X^{2}(p)$} \\
\hline & & & & .444 & 1.557 & & \\
\hline Steady & Self-efficacy & .113 & .186 & .778 & 1.611 & \multirow{3}{*}{.53} & \multirow{3}{*}{$\begin{array}{r}38.31 \\
(.0001)\end{array}$} \\
\hline \multirow[t]{3}{*}{ relationship } & Sexual sensation seeking & -.390 & .130 & .524 & .874 & & \\
\hline & Sexual frequency & -.627 & .209 & .355 & .805 & & \\
\hline & Barriers to condom use & -.019 & .280 & .567 & 1.690 & \multirow{4}{*}{.18} & \multirow{4}{*}{$\begin{array}{l}9.83 \\
(.043)\end{array}$} \\
\hline \multirow{3}{*}{$\begin{array}{l}\text { Casual } \\
\text { relationship }\end{array}$} & Self-efficacy & .407 & .180 & 1.050 & 2.130 & & \\
\hline & Sexual sensation seeking & -.126 & .063 & .770 & .998 & & \\
\hline & Sexual frequency & -.004 & .197 & .670 & 1.460 & & \\
\hline \multirow{5}{*}{$\begin{array}{l}\text { After } \\
\text { alcohol use }\end{array}$} & Barriers to condom use & -.175 & 1.350 & .644 & 1.093 & \multirow{5}{*}{.17} & \multirow{5}{*}{$\begin{array}{l}21.15 \\
(.001)\end{array}$} \\
\hline & Self-efficacy & .239 & .091 & 1.062 & 1.520 & & \\
\hline & Sexual sensation seeking & -.422 & .277 & .887 & 2.620 & & \\
\hline & Sexual frequency & -.100 & .037 & .842 & .973 & & \\
\hline & Gender equal context & .937 & .447 & 1.062 & 6.133 & & \\
\hline
\end{tabular}

Note. $\mathrm{B}=$ beta $; \mathrm{OR}=$ Odds ratio; $\mathrm{CI}=$ Confidence Interval; $\mathrm{R}^{2}=\mathrm{R}$ square. 